\title{
PEMANFAATAN SERBUK ARANG CANGKANG KELAPA SAWIT SEBAGAI SUBSTITUSI CARBON BLACK UNTUK BAHAN PENGISI KOMPON KARET
}

\section{UTILIZING CHARCOAL POWDER OF PALM OIL SHELL AS THE SUBTITUTE OF CARBON BLACK FOR RUBBER COMPOUND FILLER}

\author{
Zainal Abidin Nasution dan Harry P Limbong \\ Balai Riset dan Standardisasi Industri Medan \\ Jl. Sisingamangaraja No. 24 Medan \\ e-mail : zainal_an7@yahoo.com
}

Diterima : 18-01-2017

Direvisi : 16-05-2017

Disetujui : 05-06-2017

\begin{abstract}
ABSTRAK
Penelitian ini dilaksanakan untuk mengetahui pengaruh perlakuan pemberian serbuk arang cangkang kelapa sawit diawal dan diakhir dari penggilingan/pencampuran pada rancangan formula pembuatan contoh kompon karet. Serbuk arang cangkang kelapa sawit yang digunakan sebagai bahan pengisi (filler) dengan ukuran lolos ayakan 200 mesh (ukuran partikelnya adalah 74 mikron atau 0,074 $\mathrm{m \mu}$ ) adalah berasal dari hasil penyangraian cangkang kelapa sawit. Percobaan pembuatan kompon karet, formulasinya adalah RSS/SBR/ACS dimana phr (100/30/50) dan (100/30/60) dengan pemberian serbuk arang cangkang kelapa sawit adalah diawal dari penggilingan/pencampuran. Kemudian percobaan pembuatan kompon karet berikutnya, dengan formulasi RSS/SBR/ACS dimana phr $(100 / 30 / 50)$ dan (100/-/40) dengan perlakuan pemberian serbuk arang cangkang kelapa sawit adalah diakhir dari penggilingan/pencampuran. Parameter yang diuji adalah waktu pemasakan kompon karet, kekerasan, kekuatan tarik, modulus $300 \%$, perpanjangan putus dan kekuatan sobek. Hasil uji yang baik adalah dari formulasi RSS/SBR/ACS dimana phr (100/-/40) yaitu formulasi pembuatan contoh kompon karet pada pemberian serbuk arang cangkang kelapa sawit diakhir daripada penggilingan/pencampuran. Hasil uji yang diperoleh adalah kekuatan tarik $=132 \mathrm{~kg} / \mathrm{cm}^{2}$, modulus $300 \%=23$ psi, perpanjangan putus $=689 \%$ dan kekuatan sobek $=26 \mathrm{kgf} / \mathrm{cm}^{2}$. Sedangkan kekerasannya dari seluruh formula yang dicobakan adalah yang terendah yaitu kekerasan $=48-$ 49 shore $-A$.
\end{abstract}

Kata kunci : arang cangkang kelapa sawit, kompon karet, penyangraian cangkang kelapa sawit carbon black

\begin{abstract}
The study was conducted to determine the effect of pre-and post-mixing treatment of adding charcoal powder of palm oils shell to the designed formula of the making of rubber compound sample. The palm oil shell charcoal powder used is derived from roasting palm shells with a particle size of 200 mesh sieve passes (particle size of 74 micron). Variation of the experiment is the formulation of RSS/SBR/ACS with phr (100/30/50) and (100/30/60) with the provision of palm oil shell charcoal at the beginning of the milling/mixing. Then the formulation RSS/SBR/ACS with phr (100/30/50) and (100/-140) with charcoal treatment by giving palm oil shells powder at the end of the milling/the mixing. The parameter tested were rubber compound cooking time, hardness, modulus $300 \%$, elongation at break and tear strength. A good test result is gotten from the formulation of RSS/SBR/ACS with (100/-140) phr, that is the formulation of the production of rubber compound sample on the adding of palm oil shell powder at the end of the milling/mixing. The finding of this research shows the result of the test as the following: tensile strength $=132 \mathrm{~kg} / \mathrm{cm}^{2}$, modulus $300 \%=23$ psi, elongation at break $=689 \%$ and tear strength $=26 \mathrm{~kg} / \mathrm{cm}^{2}$. On the other hand, the hardness of all tested formula was at the lowest level of hardness that is at 48-49 shore-A.
\end{abstract}

Keywords : palm oil shell charcoal powder, the roasting of palm shell rubber compound, carbon black

66 Zainal Abidin Nasution dan Harry P Limbong

Pemanfaatan Serbuk Arang Cangkang Kelapa Sawit sebagai

Substitusi Carbon Black untuk Bahan Pengisi Kompon Karet 


\section{PENDAHULUAN}

uas lahan perkebunan kelapa sawit di Indonesia tahun 2015 mencapai 10.701.436 $\mathrm{Ha}$, dengan rincian perkebunan kelapa sawit rakyat 4.810.271 $\mathrm{Ha}$, perkebunan kelapa sawit BUMN $704.094 \mathrm{Ha}$ dan perkebunan kelapa sawit swasta 5.207.071 Ha,dengan total produksi Tandan Buah Segar (TBS) adalah 30.948.931 ton TBS (Anonim, 2014).

Menurut Pardamaian (2008) basis satu ton Tandan Buah Segar Kelapa Sawit (TBS), akan menghasilkan $20 \%-23 \%$ CPO, $5 \%$ - 7 \% PKO dan sisanya berupa limbah padat, yaitu $20 \%$ - $23 \%$ tandan kelapa sawit, $10 \%-12 \%$ serat buah kelapa sawit dan $7 \%-9 \%$ cangkang kelapa sawit.

Menurut Naibaho (1996) setiap Pabrik Kelapa Sawit (PKS) selalu dilengkapi dengan boiler sebagai generator uap yang digunakan untuk keperluan proses produksi dan menggerakkan turbin uap sebagai pembangkit tenaga listrik dalam rangka menjalankan mesin-mesin pengolahan $\mathrm{CPO}$, penerangan dan lainnya. Bahan bakar yang digunakan untuk boiler adalah limbah padatnya, yaitu serat buah sawit dan cangkang kelapa sawit. Konsumsi bahan bakar untuk boiler PKS dengan kapasitas olah 30 tonTBS/jam adalah 3,8 ton/jam serat buah kelapa sawit dan 1,5 ton cangkang kelapa sawit. Dari proses produksi PKS dengan kapasitas 30 ton TBS per jam akan diperoleh limbah padatnya adalah 3,0 ton - 3,6 ton serat buah sawit dan 2,1 ton $-2,7$ ton cangkang kelapa sawit, atau kalau dirata-ratakan sekitar 2,4 ton cangkang kelapa sawit. Pemakaian serat buah sawit sebagai bahan bakar boiler, adalah maksimal artinya semua serat buah kelapa sawit terpakai untuk bahan bakar boiler. Artinya masih tersisa sekitar rata-rata 0,9 ton/jam cangkang kelapa sawit dari proses produksi PKS dengan kapasitas 30 ton TBS per jam. Andaikan setiap hari beroperasi selama 10 jam, maka akan diperoleh rata-rata 9 ton cangkang kelapa sawit yang dapat dimanfaatkan untuk berbagai keperluan, antara lain adalah bahan baku pembuatan serbuk arang cangkang kelapa sawit sebagai Carbon Black.

Menurut Ramadhan (2014) para peneliti sekarang ini sedang memfokuskan penelitian untuk mengembangkan bahan pengisi yang bersifat menguatkan untuk mensubstitusi Carbon Black dalam kompon karet. Carbon Black yang terbuat dari minyak bumi, sumbernya mulai terbatas serta dapat menyebabkan polusi dan indikasi karsinogenik bagi pembuat kompon karet. Sebagai alternatif antara lain adalah arang cangkang kelapa sawit.

Banyak sudah penelitian yang dilakukan tentang pembuatan arang cangkang kelapa sawit dengan bermacammacam perlakuan, seperti yang telah dilaksanakan oleh Muhammad Halim dkk (2009), Haji (2010) dan Djoko Purwanto (2011).

Menurut Rahmawati (2009) arang cangkang kelapa sawit dapat digunakan sebagai bahan pengisi (filler) kompon karet, karena kemiripan struktur permukaan, luas area dan bilangan Iodine hampir mendekati karakteristik Carbon Black eks impor. Sesuai dengan parameter yang ditetapkan pada SNI.9712:2010 tentang Karbon Hitam Untuk Produk Ban dan Karet lainnya, merupakan revisi dari SNI.06 0712 -1989 tentang Hitam Karbon Untuk Ban Jenis ISAF N 220 (ukuran partikel 0,020 mikron - 0,025 mikron), meliputi pengujian bilangan Iodine, absorbsi minyak Linseed, kekerasan butiran dan logam (Cu dan Mn).

Berat jenis arang cangkang kelapa sawit adalah 0,45 gr/cm $\mathrm{cm}^{3} \quad 0,50 \mathrm{gr} / \mathrm{cm}^{3}$ (www.slideshare,net/SS/70952/gasifikasi_p elatihan_bahan_biomass, 2016).

Berat jenis curah (pour density) Carbon Black N 330 (ukuran partikel 0,026 mikron - 0,030 mikron) adalah 0,025 $\mathrm{gr} / \mathrm{cm}^{3}$.(http://MAKROchemsp.zo.ul.Bursaki 19,20 - 150 Lubin Poland, diakses tgl. 12 Mei 2016).

Carbon Black adalah arang halus dari pembakaran yang tidak sempurna dari 
berbagai material, antara lain seperti bahan bakar fosil, biofuel maupun biomassa. Pasar Carbon Black di Indonesia terus meningkat. Perkiraan konsumsi Carbon Black untuk industri yang membutuhkannya pada tahun 2016 diperkirakan 55.000 ton. Pasar Carbon Black sebagai bahan baku maupun pembantu di Indonesia meliputi industri karet, pigment hitam pada pembuatan plastik, cat, karpet mobil, karpet drainase untuk rumah/hotel, karpet sapi, sandal, sol sepatu, aspal, kabel listrik, pipa, film plastik, karet-karet otomotif dan lainnya. Harga Carbon Black dipasaran pada tahun 2015, berkisar antara Rp.7.000 per kg s/d Rp.20.000 per kg tergantung pada jenis dan kualitasnya. (www.Carbon lack. CV.BINAJAYA.Indonetwork.co.id, 2016).

Kompon karet adalah merupakan turunan yang paling utama dari komoditi karet. Hampir semua kompon karet, menggunakan Carbon Black sebagai bahan pengisi (filler). Bahan pengisi Carbon Black berfungsi sebagai penguat (reinforcing), memperbesar volume, memperbaiki sifatsifat fisik dari barang-barang karet dan memperkuat vulkanisat (Boonstra dalam Prasetya, 2013).

Proses pembuatan kompon karet adalah proses pencampuran antara karet mentah dan bahan-bahan kimia karet (aditip). Bahan - bahan kimia untuk membuat kompon karet adalah seperti berikut :

a. Accelerator (bahan pencepat). Merupakan senyawa kimia yang ditambahkan untuk mempercepat proses vulkanisasi kompon karet. Beberapa keuntungan yang dapat diperoleh dengan menambahkan bahan pencepat adalah :

- dapat menggunakan bahan dasar karet kualitas rendah

- dapat memperbaiki penampilan dan kemampuan untuk diberi warna

- meningkatkan daya tahan terhadap aging (penuaan)

Bahan pencepat yang digunakan dapat berupa satu atau kombinasi dari dua atau lebih jenis bahan pencepat. Jenisnya antara lain adalah bahan semi cepat (MBT, MBTS) dan bahan cepat ditunda.

b. Filler (bahan pengisi). Berdasarkan klasifikasinya, filler dibedakan atas :

- Reinforcingfiller, selain berfungsi sebagai bahan pengisi juga akan mempengaruhi sifat-sifat fisik (menambah kekuatan tarik, daya tahan terhadap gesekan dan lainnya). Yang dimaksud dengan filler tersebut adalah carbon black.

- Inert filler, hanya berfungsi sebagai penambah volume saja. Contohnya : bentonit, kalsium karbonat, kaolin dan lainnya.

c. Bahan pemvulkanisasi.

Bahan pemvulkanisasi adalah bahan kimia yang dapat bereaksi dengan gugus aktif pada molekul karet, membentuk ikatan silang tiga dimensi. Paling umum digunakan adalah Sulfur (belerang) yang khusus digunakan untuk vulkaniser karet alam atau karet sintetis, misal : SBR, NBR, IR dan EPDM.

d. Anti Oksidan

Penambahan anti oksidan pada kompon karet akan menghambat kerusakan karet karena udara $\left(\mathrm{O}_{2}\right)$, sinar matahari dan ozon. Karet tanpa anti oksidan akan mudah teroksidasi sehingga menjadi lunak, kemudian lengket dan akhirnya menjadi keras dan retak-retak. Pemakaian anti oksidan harus memenuhi beberapa syarat, yaitu mudah terdispersi pada seluruh bagian karet, inert terhadap hasil vulkanisasi dan tidak mempengaruhi warna hasil vulkaniser. Contoh anti oksidan waxes, phenol dan lainnya.

e. Bahan pelunak (softener), adalah berfungsi untuk melunakkan karet alam dan karet sintetis agar mudah diolah menjadi kompon karet. Contoh bahan pelunak adalah minarex oil dan lainnya.

Pembuatan kompon karet biasanya menggunakan alat pencampur (mixer), dapat berupa mesin giling tertutup ataupun mesin giling terbuka. Alat pencampur yang paling sederhanaadalah mesin giling terbuka yang terdiri dari dua rol stainless steel. 


\section{BAHAN DAN METODE}

\section{Bahan dan alat}

Bahan bakunya adalah cangkang kelapa sawit yang berasal dari limbah proses PKS Padang Brahrang, Kabupaten Langkat, Provinsi Sumatera Utara. Bahanbahan kimia yang digunakan dalam penelitian untuk pembuatan contoh kompon karet adalah RSS-20, SBR, Minarex Oil, ZnO, Stearic Acid, TMQ, MBTS, Bentonit, Coumarin Resin, Anti Oksidan dan Sulfur. Bahan-bahan kimia untuk pembuatan contoh kompon karet dibeli dari PTWilqis (Inkaba) di Bandung.
Peralatan yang digunakan untuk membuat contoh kompon karet adalahTwo Roll Mixing Mill For Rubber, Timbangan, NeracaAnalitis, Gunting Besar dan Kecil, Kuali Besi, Lumpang Besi, Kompor, Wadahwadah, Sudip, Termometer Air Raksa Skala $360^{\circ} \mathrm{C}$ dan lainnya. Contoh kompon karet dibuat di Laboratorium Teknologi Baristand Industri Palembang di Palembang.

Pembuatan Serbuk Arang Cangkang Kelapa Sawit

Percobaan pembuatan serbuk arang cangkang kelapa sawit dilaksanakan dengan metode penyangraian.

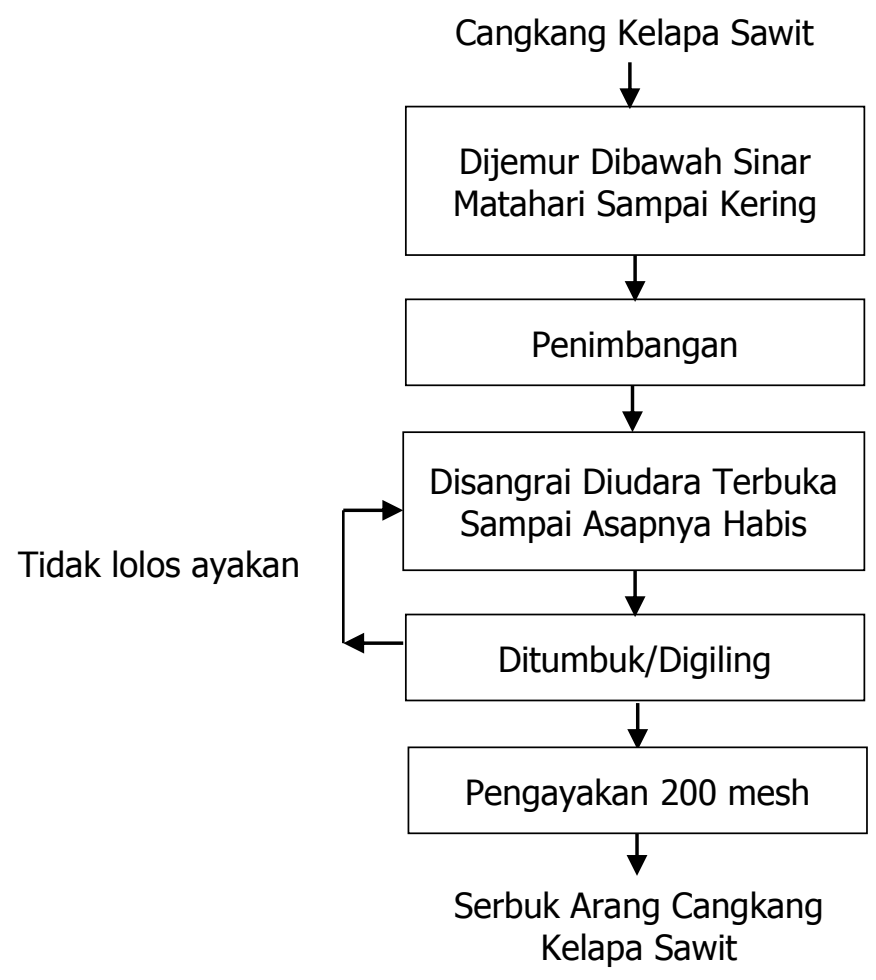

Gambar 1. Diagram Alir Percobaan Pembuatan Serbuk Arang Cangkang Kelapa Sawit

\section{Pembuatan Kompon Karet Dengan Bahan Pengisi Serbuk Arang Cangkang Kelapa Sawit Hasil Penyangraian}

Prosedur pembuatan contoh kompon karet pada penelitian ini adalah sebagai berikut :

a. Penimbangan bahan bahan.

Semua bahan-bahan dari masingmasing formula ditimbang sesuai dengan yang telah ditentukan.

b. Mixing/blending (pencampuran). c. Proses pencampuran dilakukan pada gilingan terbuka (open mill), seperti berikut :

- Mastikasi (menghomogenkan) RSS dan SBR selama 6 menit s/d 7 menit

- Menambahkan bahan-bahan kimia sesuai dengan urutan pada masingmasing formula dan digiling/ pencampuran sampai diperoleh berupa lembaran, dan dipotong-potong untuk digiling kembali sampai tiga kali selama 2 menit s/d 3 menit, agar 
bahan bahan kimia menjadi homogen pada lembaran kompon karet.

- Mencampurkan belerang hingga mencapai kematangan yang diinginkan - Kompon karet dikeluarkan dari open mill dan buat ukuran ketebalan lembaran kompon karet, keluarkan dan ditutup dengan plastik transparan bagian atas dan bagian bawah, diperam selama 24 jam agar bahanbahan kimia bereaksi secara sempurna. - Contoh kompon karet hasil penelitian diuji sifat-sifat fisiknya di laboratorium PT .Wilqis di Bandung.

\section{Metode Dan Analisa Data}

Parameter yang diuji dari kompon karet hasil penelitian adalah :

- waktu pemasakan kompon, rheometer (ASTM D- 5289) ;

- kekerasan (ASTM

D2240) ;kekuatan tarik (ASTM D-412);

- modulus (ASTM D-412) perpanjangan putus (ASTM D-412) ;

- kekuatan sobek ( (ASTM D-624)

Tabel 1. Formula Pembuatan Kompon Karet (Pemberian Arang Cangkang Kelapa Sawit Diawal Penggilingan/Pencampuran)

\begin{tabular}{cccc}
\hline & & \multicolumn{2}{c}{ Suhu Rol $70^{\circ} \mathrm{C}$} \\
\cline { 3 - 4 } No & Nama Bahan & \multicolumn{2}{c}{ Formulasi RSS/SBR/ACS (phr) } \\
\cline { 3 - 4 } & & $100 / 30 / 50$ & $100 / 30 / 60$ \\
\hline 1. & RSS-20 & 100 & 100 \\
\hline 2. & SBR & 50 & 30 \\
\hline 3. & Arang Cangkang Sawit & 20 & 60 \\
\hline 4. & Minarex Oil & 10 & 20 \\
\hline 5. & ZnO & 10 & 10 \\
\hline 6. & Stearic Acid & 20 & 10 \\
\hline 7. & TMQ & 20 & 20 \\
\hline 8. & MBTS & - & 20 \\
\hline 9. & Bentonit & 8 & 30 \\
\hline 10. & Sulfur & 268 & 312 \\
\hline & Jumlah & & \\
\hline
\end{tabular}

Tabel 2. Formula PembuatanKompon Karet (Pemberian Serbuk Arang Cangkang Kelapa Sawit Diakhir Penggilingan/Pencampuran)

\begin{tabular}{cccc}
\hline \multirow{2}{*}{ No } & \multirow{2}{*}{ Nama Bahan } & \multicolumn{2}{c}{ Suhu Rol $70^{\circ} \mathrm{C}$} \\
\cline { 3 - 4 } & & $100 / 30 / 50$ & $100 /-/ 40$ \\
\hline 1. & RSS-20 & 100 & 100 \\
\hline 2. & SBR & 30 & - \\
\hline 3. & ZnO & 4 & 4 \\
\hline 4. & Stearic Acid & 2 & 2 \\
\hline 5. & CBS & 1 & 1 \\
\hline 6. & MBTS & 2 & 2 \\
\hline 7. & Coumarin Resin & 4 & 40 \\
\hline 8. & Arang Cangkang Sawit & 50 & 4 \\
\hline 9. & Minarex Oil & 7 & 2 \\
\hline 10. & Sulfur & 3 & 156 \\
\hline & Jumlah & 203 & \\
\hline
\end{tabular}




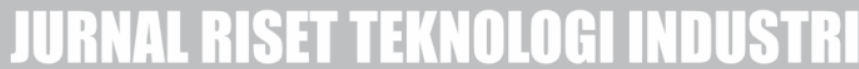

HASIL DAN PEMBAHASAN

a. Hasil Penelitian

Dari hasil pengujian contoh diperoleh data - data sebagai berikut :

\section{b. Pembahasan}

Dari data - data tersebut diatas dapat dibahas sebagai berikut:

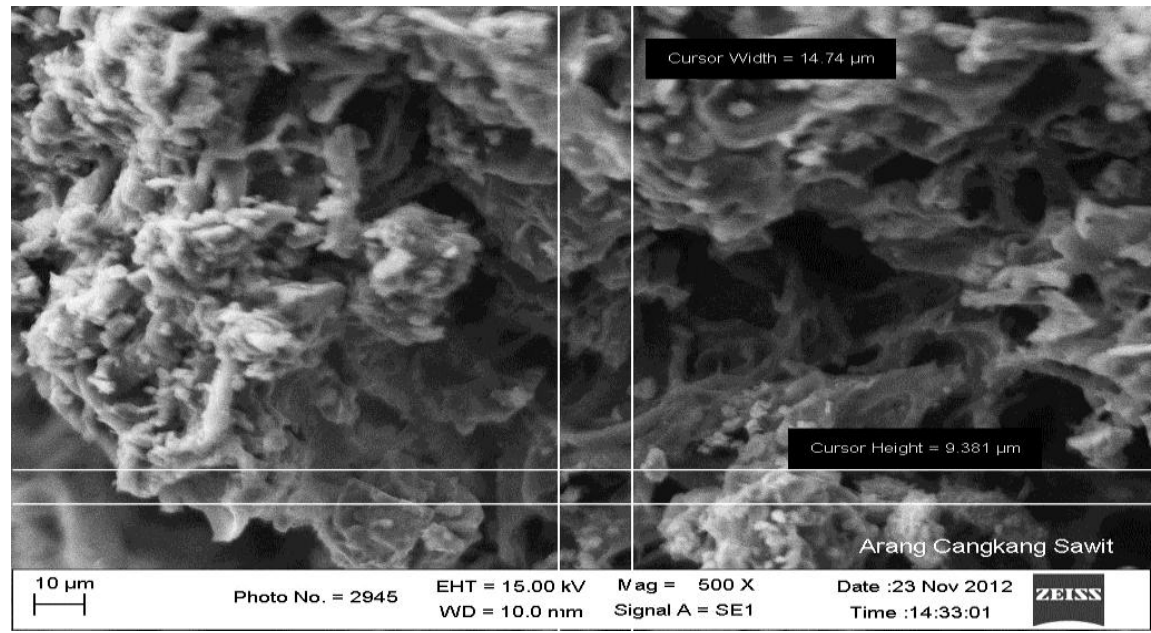

Gambar 2. Foto SEM Arang Cangkang Sawit Pembesaran 500

Tabel 3. Hasil Pengujian Kompon Karet

\begin{tabular}{llcccc}
\hline \multirow{2}{*}{ No } & Pengujian & \multicolumn{4}{c}{ Hasil Uji Formulasi RSS/SBR/ACS (phr) } \\
\cline { 3 - 6 } & $\begin{array}{c}100 / 30 / \\
50\end{array}$ & $\begin{array}{c}100 / 30 \\
/ 60\end{array}$ & $100 / 30 / 50$ & $100 /-/ 40$ \\
\hline 1. & Rheometer & & & & \\
\hline & ML (mm), dn.m & 0,40 & 0,05 & 0,55 & 0,58 \\
\hline & MH (maks) dn.m & 23,28 & 25,47 & 10,80 & 12,26 \\
\hline & Tc 10, menit & 3,22 & 5,08 & 5,10 & 2,55 \\
\hline & Tc 90, menit & 8,06 & 10,24 & 10,53 & 6,34 \\
\hline 2. & Hardness, Shore-A & $74-75$ & $66-67$ & $45-46$ & $48-49$ \\
\hline 3. & Tensile Strength, kg/cm ${ }^{2}$ & 63 & 19 & 78 & 132 \\
& Modulus 300\%,psi & 29 & 18 & 18 & 23 \\
\hline 4. & Elongation at Break, \% & 240 & 230 & 680 & 689 \\
\hline 5. & Tear Resistence, $\mathrm{kg} / \mathrm{cm}$ & 21 & 21 & 14 & 26 \\
\hline & & & & & \\
\hline
\end{tabular}

\section{Pembuatan Arang Cangkang Kelapa Sawit Dengan Cara Penyangraian}

Dari percobaan pembuatan arang cangkang kelapa sawit dengan metode penyangraian, rendemen hasilnya adalah rata-rata 38,20 \% (yaitu diperoleh pada suhu terakhir $348{ }^{\circ} \mathrm{C}$, dimana proses penyangraian dihentikan pada saat asap sudah habis, dinyatakan pirolisis sudah selesai).

Hasil penelitian Halim dkk (2009) pembuatan arang cangkang sawit menggunakan metode reaktor pirolisis dengan mempertahankan suhu pembakaran sebesar $400{ }^{\circ} \mathrm{C}$ dan lamanya proses pembakaran adalah 90 menit, diperoleh rendemen rata rata arang cangkang kelapa sawit sebesar $41 \%$.

Hasil penelitian Haji dkk (2010) pembuatan arang cangkang kelapa sawit menggunakan metode pembakaran tertutup dengan mempertahankan suhu pembakaran sebesar $378{ }^{\circ} \mathrm{C}$ dan lamanya proses pembakaran adalah 5 jam, kemudian api didalam tungku dipadamkan dengan menyiramkan air dan dibiarkan dingin secara alami. Rendemen rata rata arang cangkang kelapa sawit adalah $38,31 \%$. 
Menurut Yokoyama (2008) bahwa pirolisis biomassa berakhir pada bagian lignin yaitu pada suhu $280{ }^{\circ} \mathrm{C} \mathrm{s} / \mathrm{d} 500^{\circ} \mathrm{C}$. Dilihat dari rendemen dan suhunya, ternyata tidak terjadi perbedaan yang signifikan dengan penelitian lainnya, yaitu dari hasil penelitian diperoleh rendemen arang cangkang kelapa sawit adalah $38,20 \%$ dan suhu terakhir penyangraian adalah $348^{\circ} \mathrm{C}$.

\section{Perbedaan Struktur Antara Carbon Black Dan Serbuk Arang Cangkang Kelapa Sawit.}

Carbon Black adalah sebuah serbuk yang sangat halus dengan luas permukaan sangat besar dan terdiri hanya dari atom karbon.Carbon Black merupakan material nano yang paling banyak dan agregatnya berukuran dari belasan sampai ratusan nanometer dimana ukuran tertentu akan memberikan sifat tertentu pada komposit dimana Carbon Black digunakan. (www. scribd.com/doc/59066912/Proses-ProduksiCarbon-Black, 2016).

Arang adalah residu hitam berisi karbon tidak murni yang dihasilkan dari proses pembakaran bahan yang mengandung unsur karbon. Arang umumnya didapatkan dari bahan baku yang mengandung karbon, umumnya dari tumbuh-tumbuhan, antara lain adalah cangkang kelapa sawit. (www. id/apa-sihbedanya-arang-dengan-arang aktif, 2016).

Menurut Haji dkk (2010) dari percobaan foto SEM serbuk arang cangkang kelapa sawit ukuran 100 mesh, terjadi perubahan pola topografi permukaan arang cangkang kelapa sawit, akibat proses pirolisis, yaitu terbentuknya pori-pori. Pori-pori tersebut terbentuk karena zat-zat yang ada pada serbuk cangkang kelapa sawit menguap sehingga terjadi rongga atau pori-pori pada struktur serbuk arang cangkang kelapa sawit.

\section{Pembuatan Kompon Karet Dengan Bahan Pengisi Serbuk Arang Cangkang Kelapa Sawit Hasil Penyangraian}

Arang cangkang kelapa sawit yang diperoleh dari metode penyangraian, ditumbuk/digiling ampai menjadi serbuk dan diayak dengan ayakan lolos 200 mesh (ukuran partikel 74 mikron).

Serbuk arang cangkang kelapa sawit tersebut harus dibuat hasil ujinya, untuk mengetahui apakah dapat berfungsi sebagai bahan pengisi (filler) kompon karet.

Penjelasan tentang parameter yang diujikan kepada kompon karet adalah seperti berikut :

\section{Kekerasan}

Kekerasan suatu kompon karet bisa diartikan sebagai tekanan balik dari kompon karet pada saat kompon karet tersebut diberikan tekanan. Kekerasan karet tergantung kepada peranan bahan pengisi dan bahan pelunak yang digunakan pada penyusunan campuran vulkanisat. Penambahan bahan pengisi menyebabkan kerapatan ikatan silang akan naik, sehingga kompon karet menjadi semakin keras. Sedangkan bahan pelunak digunakan agar memudahkan penggilingan karet mentah (melunakkan karet).

Kekuatan tarik merupakan pengujian fisik kompon karet yang terpenting dan paling sering dilakukan. Sehingga dari pengujian ini dapat diketahui waktu vulkanisasi optimum suatu kompon karet dan pengaruh pengusangan pada suatu proses vulkanisasi.

$$
\text { Menurut Sasongko }
$$

penelitian yang diamatinya tentang pengaruh jumlah phr carbon black dan ukuran partikel carbon black. Jumlah carbon black yang diteliti pada 30,40 dan $50 \mathrm{phr}$ dengan pemakaian carbon black $\mathrm{N}$ 220, N330, N 550 dan N 660. Dari hasil yang diperoleh dapat disimpulkan bahwa ukuran partikel memberikan pengaruh terhadap kekuatan tarik dari kompon. Sedangkan untuk peningkatan phr yang lebih besar secara linier akan memberikan pengaruh terhadap kekerasan dari kompon karet.

Dari hasil pengujian kompon karet dapat diketahui bahwa pada arang cangkang kelapa sawit yang diberikan diawal penggilingan / pencampuran, 
vulkanisat karet tidak masuk kedalam pori-pori arang cangkang kelapa sawit. Arang cangkang kelapa sawit bertindak sebagai aggregat, yaitu berada dicelahcelah antara butiran arang cangkang kelapa sawit diisi oleh vulkanisat karet, sehingga kekerasannya menjadi tinggi.

\section{Modulus $300 \%$}

Menurut ASTM - 412, maksudnya adalah tensile stress yang terjadi pada $300 \%$ perpanjangan (elongation). Contoh, bila tensile stress adalah 100 psi, artinya modulus $300 \%$ adalah 100 psi.

\section{Kekuatan Tarik dan Perpanjangan Putus}

Kekuatan tarik merupakan pengujian fisik kompon karet yang terpenting dan paling sering dilakukan. Sehingga dari pengujian ini dapat diketahui waktu vulkanisasi optimum suatu kompon karet dan pengaruh pengusangan (penuaan) pada suatu proses vulkanisasi.

Selain daripada itu diketahui bahwa nilai perpanjangan putus berbanding lurus dengan nilai kekuatan tarik. Semakin tinggi nilai tegangan putus berarti energi yang digunakan untuk memutuskan vulkanisat semakin besar. artinya ikatan silang yang terbentuk semakin banyak. Ikatan silang yang terbentuk semakin banyak menyebabkan elastisitas vulkanisat menjadi lebih baik. Sehingga kemampuan vulkanisat untuk memanjang semakin bagus dan nilai perpanjangan putusnya semakin tinggi.

Dari Gambar - 2, foto SEM arang cangkang kelapa sawit untuk perbesaran $500 \times$ (masih utuh belum digiling), dapat dilihat pori-porinya dimana sebagai contoh adalah cursor height $=9,381$ mikron $=$ $0,0094 \mathrm{~m} \mu$ dan cursor width $=14,74$ mikron $=0,0147 \mathrm{~m} \mu$. Serbuk arang cangkang kelapa sawit yang digunakan adalah lolos ayakan 200 mesh (ukuran partikel $=74$ mikron $=0,0740 \mathrm{~mm}$ ). Pada arang cangkang kelapa sawit yang diberikan diakhir penggilingan/ pencampuran, maka butiran pori-pori ataupun rongga, akan diisi oleh karet yang sudah lunak/matang tadi. Jadi arang cangkang kelapa sawit, tidak bertindak sebagai aggregat saja, yaitu vulkanisat karet bukan hanya berada dicelah-celah butiran arang cangkang kelapa sawit. Tetapi juga masuk kedalam pori-pori ataupun rongga pada arang cangkang kelapa sawit tersebut, menyebabkan kompon karet menjadi kuat dan kaku.

\section{Ketahanan sobek}

Ketahanan sobek menunjukkan tenaga yang dibutuhkan untuk menyobek vulkanisat karet. Kekuatan sobek akan terus meningkat sejalan dengan pertambahan jumlah ikatan silang pada proses vulkanisasi (Eirich dalam Pireno, 2013).

Berdasarkan percobaan pengujian fisik contoh kompon karet hasil penelitian dengan ukuran partikel arang cangkang kelapa sawit adalah 200 mesh ( 74 mikron), dimana formula pembuatan contoh kompon karetnya seperti yang terlihat pada Tabel - 1 dan Tabel - 2, dimana hasilnya pada Tabel -3 .

Dari Tabel-3, dapat dilihat hasil pengujian kompon karet dari pemberian bahan-bahan aditif sesudah terjadinya peristiwa adsorbsi molekul karet pada poripori arang cangkang sawit (pemberian arang cangkang kelapa sawit diawal penggilingan/pencampuran) dan pemberian bahan-bahan aditif sebelum terjadinya peristiwa adsorbsi molekul karet pada pori-pori arang cangkang kelapa sawit (pemberian arang cangkang kelapa sawit sesudah penggilingan/pencampuran), yaitu :

a. Pemberian arang cangkang kelapa sawit diawal penggilingan, akan menghasikan kekerasan yang lebih kuat dari pada pemberian arang cangkang kelapa sawit diakhir penggilingan.

b. Pemberian arang cangkang kelapa sawit diakhir penggilingan akan menghasilkan kekuatan tarik dan perpanjangan putus yang lebih kuat dari pemberian arang cangkang kelapa sawit diawal penggilingan.

\section{KESIMPULAN DAN SARAN Kesimpulan}

Dari hasil penelitian dapat disimpulkan bahwa Carbon Black asal arang cangkang kelapa sawit dapat 
digunakan sebagai bahan pengisi (filler) kompon karet.

Hasil pengujian fisik dengan perlakuan pemberian bahan-bahan aditif sesudah arang cangkang kelapa sawit digiling/dicampur dan perlakuan pemberian bahan-bahan aditif sebelum arang cangkang kelapa sawit digiling/ dicampur menunjukkan, bahwa pemberian arang cangkang kelapa sawit diawal penggilingan/ pencampuran akan menghasilkan kekerasan yang lebih baik daripada pemberian arang cangkang kelapa sawit diakhir penggilingan/ pencampuran kekuatan tarik = 132 $\mathrm{kg} / \mathrm{cm}^{2}$, modulus $300 \%=23 \mathrm{psi}$, perpanjangan putus $=689 \%$ dankekuatan sobek $=26 \mathrm{kgf} / \mathrm{cm}^{2}$. Kemudian pemberian arang cangkang kelapa sawit diakhir penggilingan/pencampuran akan menghasilkan kekuatan tarik dan perpanjangan putus yang lebih kuat daripada pemberian arang cangkang kelapa sawit diawal dari penggilingan/pencampuran.

\section{Saran}

Agar diperoleh data/informasi yang lebih luas dan lengkap, penelitian perlu dilanjutkan, yaitu percobaan pembuatan kompon karet dengan perlakuan ukuran butiran dan jumlah phr dari arang cangkang kelapa sawit, untuk pemberian diawal maupun diakhir penggilingan/ pencampuran.

\section{DAFTAR PUSTAKA}

Anonimous, 2010, Pembuatan Produk Karet dan Plastik, Scribd, Balai Besar Kulit, Karet dan Plastik, Yogyakarta.

Anonimous, 2014, Statistik Perkebunan Indonesia Krlapa Sawit 2012 - 2015, Ditjend, Kementan.

Haji, AG, G. Pari, Habibati, Amiroddin dan Maulina, 2010, Kajian Mutu Arang Hasil Pirolisis Cangkang Kelapa Sawit, Jurnal Purifikasi, Vol. II No. 1, hal. 77-86.

Halim, M, P Darmadji dan R Indrati, 2009, Fraksinasi dan Identifikasi Senyawa Volatil Asap Cair Cangkang Sawit, Agritech Vol 23 No 3, hal.117-123.
Haryadi B dan Syamsul Bahri, 2006, Pemanfaatan Arang Tempurung Kelapa dan Arang Kelapa Sawit Sebagai Bahan Pengisi Kompon Karet, Abstrak, Dinamika Penelitian BIPA, Vol. 17 No. 30.

Marlina, P dan Dewantara Daud, 2009, Penggunaan Minyak Biji Karet Sebagai Pelunak Karet, Jurnal Industri Hasil Perkebunan, Vol 4 No 1 , hal.8-13.

Naibaho, PM, 1996, Teknologi Pengolahan Kelapa Sawit, PPKS Medan.

Nuyah dan Rahmaniar, 2013, Pembuatan Kompon Karet Dengan Bahan Pengisi Arang Cangkang Sawit, Jurnal Dinamika Penelitian Industri, Vol. 24 No. 2, hal. 114-121.

Okroigwe, E C, C M Saffron and P D Kamdem, 2014, Characterization Of Palm Kernell Shell For Materials Reinforcement And Watwer Treatment, Journal Of Chemical Engineering And Materials Science, Vol 5 No 1.

Pardamean, M, 2008, Panduan Lengkap Pengelolaan Kabun dan Pabrik Kelapa Sawit, Cetakan Pertama, Pustaka Angromedia, Jakarta.

Pireno, CA, Agus Wijaya dan Rindit Pambayun, 2013, Pengaruh Suhu dan Waktu Vulkanisasi Terhadap Karakteristik Kompon Sol Karet Berbahan Pengisi Arang Cangkang Sawit, Jurnal Dinamika Penelitian Industri, Vol. 24 No. 1, hal. 31-38.

Prasetya HA dan Poppy Marlina, 2013, Penggunaan Sekam Padi Sebagai Bahan Pengisi dan Antioksidan Pada Pembuatan Kompon Karet, Jurnal Dinamika Penelitian Industri, Vol. 24 No. 2, hal. $66-73$.

Ramadhan,A, B Soegijono Fathurrohman, 2014, Pegaruh Organobentonit Dan Asam Stearat Terhadap Karakteristik Pematangan Dan Sifat Mekanik Vulkanisat Karet Alam.Jurnal Penelitian Karet,Vol.32 No.1,hal.4555.

Purwanti, D, 2011, Arang Dari Limbah Tempurung Kelapa Sawit,Jurnal 
Penelitian Hasil Hutan,Vol 29 No, 1,hal.5766.

Rahmawati, 2009, Pengaruh Komposisi Arang Cangkang Kelapa Sawit dan Hitam Arang (Carbon Black) Terhadap Kualitas Kompon Karet Sol Sepatu, Skripsi, FMIPA Universitas Sumatera Utara, Medan.

Sari D $P$, Tamrin dan DD Novita,2015,Pengaruh Suhu dan Waktu Penyangraian Terhadap Karakteristik Tulang,Artikel IImiah Teknik Pertanian Lampung,hal,45-50. Siagian, $N$, M Supriadi dan C Anwar,2010,Potensi Produksi Kayu Karet Tua Di Tingkat Petani Dan Perkebunan Serta Kendala Dalam Pemanfaatannya,Jurnal Penelitian Karet,Vol 28 No 1,Hal.26-43.
Sidabutar, VTP, 2014, Kajian Literatur Modifikasi Kekerasan Kompon Ditinjau Dari Elastomer, Bahan Pengisi, Proses Oil dan Accelerator, Karya Tulis ilmiah, BBPPFI, Ditjend Pengembangan Ekspor Nasional, Kemendag RI, Jakarta.

Supraptiningsih, A Buchroni dan Sri Brataningsih dan Puji Lestari, 2005, Pengaruh RSS/SBR dan Filler $\mathrm{CaCO}_{3}$ Terhadap Sifat Fisis Kompon Karet, Majalah Kulit, Karet dan Plastik, Vol. 21 No. 1, hal. 34-40.

Yokoyama, S, 2008, The Asian Biomass Handbook : A Guide for Biomass Production and Utilization, The Japan Institute of Energy. 